\title{
Significance of duck in the transmission of avian influenza virus
}

\author{
Md. Zohorul Islam ${ }^{1}$, Shahana Ahmed ${ }^{2}$, Shahneaz Ali Khan ${ }^{3}$ and Mohammad Belayet Hossain ${ }^{3}$ \\ ${ }^{1}$ Department of Microbiology, ${ }^{2}$ Department of Animal Science and animal Nutrition, ${ }^{3}$ Department of Physiology, \\ Biochemistry and Pharmacology., Chittagong Veterinary and Animal Sciences University, Khulshi-4202, E-mail: \\ sakhan2008@yhoo.com
}

Poultry enterprise is an important part of agriculture which is emerging as a strong agrobased industry in Bangladesh. But this sector is now facing a challenging situation with recent outbreaks of Avian Influenza (AI), posing a great threat to the growing poultry industry. Avian influenza is a viral disease that ranges from a mild or even asymptomatic infection to an acute, fatal disease of chickens, turkey, guinea fowls and migratory water fowls (Clavijo et al., 2003). Influenza viruses hold generic status in the Family Orthomyxoviridae and are classified into types $A$, $B$ or $C$ based on antigenic differences of their nucleo and matrix proteins. Avian influenza viruses (AIV) belong to type A (Sidoronko and Reichl, 2004). The main antigenic determinants of influenza $A$ and $B$ viruses are the haemagglutinin $(\mathrm{H}$ or $\mathrm{HA})$ and the neuraminidase ( $N$ or $N A)$ of transmembrane glycoproteins. On the basis of the antigenicity of these glycoproteins, influenza A viruses currently cluster into sixteen $\mathrm{H}(\mathrm{H} 1-\mathrm{H} 16)$ and nine N (N1-N9) subtypes (Fouchier et al., 2005). Among these types AIV, H5N1 has been proved to be more virulent (Akey, 2003). Wild aquatic birds, notably members of the orders Anseriformes (ducks and geese) and Charadriiformes (gulls and shorebirds), are the natural reservoir of all influenza $A$ viruses (Fouchier et al., 2003). The exact origin of Highly Pathogenic Avian Influenza (HPAl) in Bangladesh still remains obscure. Clearly, ducks play a complex and vital role in the biology and the overall natural history of influenza, including H5N1 HPAl viruses and most domestic grazing ducks infected with H5N1 HPAl viruses were asymptomatic (Songserm et al., 2006). The initial spread of these viruses to chickens and humans corresponded to the movement of grazing ducks (Songserm et al., 2006, Tiensin et al., 2005). In fact, infected domestic ducks grazing on manmade wetlands like harvested rice fields and irrigation canal may maintain the infection. The objective of the present study was to detect the presence of AIV in domestic ducks in Joypurhat, Bangladesh.

Sampling: The present study work was conducted at Kalai and Khetlal Upazilla under Joypurhat District, Bangladesh. A total of 75 cloacal swabs were collected from native ducks in 5 Unions. From each union 15 samples were collected randomly from 25 villages.

Detection of AIV antigen by Chromatographic immunoassay: Sample was directly collected from cloaca of ducks by the insertion of swabs. After collecting cloacal samples, each swab was inserted into a sample tube containing assay diluents and mixed until the sample dissolved in the diluents. The tube was then left until the large particles settled down in the bottom of the tube. Then five drops of supernatant were taken by a disposable dropper and added to the sample holes on the test device. As the test begins to work, purple colour will move across the result window in the centre of the test device and the interpretation of the results at 30 minutes in comparison with positive control according to the kit manufacturer's instructions. Positive result indicated presence of AIV antigen type A only.

Statistical analysis: The data were analyzed by one-way ANOVA. Values were expressed in mean \pm SD. The statistical analyses were performed using SPSS (Ver.11.5) for Windows.

The prevalence of AIV in ducks was $6.67 \%$ in Ahmedabad union, 13.33\% in Borotara union, 0\% in Punot and Matrai unions and $6.67 \%$ in Bomboo union (Table 1). However, the overall prevalence of the virus was found to be $5.33 \%$, which showed a significant difference among the villages under study $(P<0.001)$. The AIV was detected in the native ducks though there were no apparent clinical signs. It is known that the viruses multiply in the respiratory and gastrointestinal tracts and are shed through respiratory secretions and faeces prior to development of any clinical signs. This might be that the ducks were exposed to natural infections with low virulent AIV, as wild and domestic ducks are potent carriers of the virus. (Vander et al., 2003).

In the study areas, the native chickens are reared under semi-scavenging system and are allowed to scavenge with ducks in the yard, in the crop fields near water reservoirs where domestic ducks, wild ducks and migratory birds used to scavenge. This factor may contribute to the infection of the native chickens and further on to the commercial 
chickens (Alexander, 2003; De Marco et al., 2003). Moreover, another important fact was observed that the highest prevalence (13.33\%) was found in Borotara union, which is the important place of mixing of ducks with wild water birds. Because, the domestic duck may get infection from village sided river where the wild water birds are mixed together (Senne et al. (2003).

Table 1: Prevalence of Avian Influenza virus in ducks under Joypurhat District.

\begin{tabular}{lccccc}
\hline $\begin{array}{c}\text { Sources of sample } \\
\text { (union) }\end{array}$ & Tested sample $(\mathrm{n}=75)$ & Positive (\%) & Overall prevalence (\%) & Mean \pm SD & P value \\
\hline Ahmedabad & 15 & $1(6.67)$ & & & \\
Matrai & 15 & 0 & & & \\
Punot & 15 & 0 & $5.33 \%$ & $0.8 \pm 1$ & $0.0002^{\text {** }}$ \\
Borotara & 15 & $2(13.33)$ & & \\
Bomboo & 15 & $1(6.67)$ & & \\
Total & 75 & 4 & & \\
\hline
\end{tabular}

$\mathrm{SD}=$ Standard deviation, ${ }^{\star \star}=\mathrm{P}<0.001$ level of significance, $\%=$ Percentage .

The prevalence of AIV in duck was found $6.25 \%$ and $3.7 \%$ in females (ducks) and males (drakes), respectively (Fig. 2). A significant $(p<0.05)$ variation between male and female birds was found.

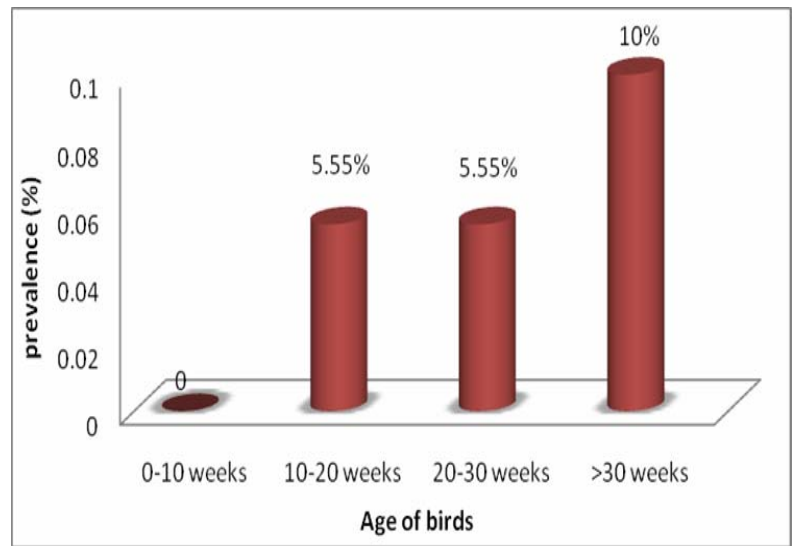

Fig.1: Prevalence of avian influenza virus in native ducks at different ages.

The prevalence of AIV based on age of birds is presented on Fig.1. It was observed that the highest prevalence $(10 \%)$ was found in the birds that are over 30 weeks old and there is absence of virus infection below 10 weeks of age. This may be due difference of immune status at various age groups of birds. Antibody against Avian influenza may be found at any age (OIE, 2003) of birds. The result showed similarity with the study conducted by Brug et al. (1987).

The prevalence was higher in female than in male ducks. It is indicated that female birds were more susceptible to avian influenza than the male birds (Halvorson et al. 1983). The possible explanation might be the stress during egg production and vulnerability of infection to the female is more. Nooruddin et al. (2006) carried out an investigation in another region of Bangladesh where a higher prevalence of avian influenza in hens (10.83\%) was found than cocks (8.65\%), which is similar to this study.

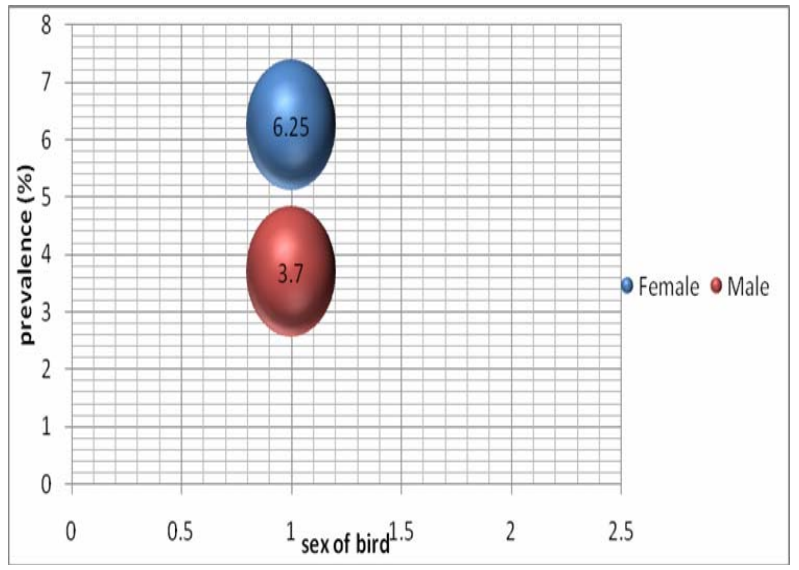

Fig.2: Prevalence of avian influenza virus in native ducks at different sexes.

Endemicity of the Asian lineage HPAIV H5N1 in migratory birds would pose a constant threat to poultry holdings. This would only be met by strict bio-security measures including a prohibition of free-roaming poultry holdings. Endemicity in wild birds may also lead to the presence of HPAI H5N1 virus in the environment such as lakes and sea shores might create an additional potential risk of exposure for humans. The purpose of the study for 
rapid AIV antigen test kit was used which is chromatographic immunoassay for the qualitative detection of (AIV) type A. But there is no way to differentiate the LPAI from HPAI viruses by this test kit. So for further investigation, most recent molecular techniques should be employed.

\section{References}

Alexander, D.J. 2003. Report on avian influenza in the Eastern Hemisphere during 1997-2002. Avi Dis. 47: 792-797.

Akey, B.L. 2003. Low pathogenicity H7N2 avian influenza outbreak in Virginia during 2002. Avi Dis. 47: 1099-1103.

Brugh, M. \& Gohnson, D.C. 1987. Epidemiology of Avian Influenza in Domestic Poultry. Proceeding of the Second International Symposium on Avian Influenza. United States Animal Health Association, Athens, GA. 177-186.

Clavijo, A., Riva, G. \& Pasick, G. 2003. Pathogenicity of a Ratite origin Influenza A H5 virus in Ostrichesb (Struthis camelus). Avi Dis. 47: 1203-1207.

De Marco, M.A., Foni, G.E., Campitelli, L., Roffini, E.L., Trani, D.I., Delogu, M., Guberti, V., Barigazzi, G. \& Donatelli, I. 2003. Circulation of influenza viruses in waterfowl wintering in Italy during the 1993-1999 periods: Evidence of virus shedding and seroconversion in wild ducks. Avi Dis. 47: 861- 866.

Fouchier, R.A., Olsen, B. \& Bestebroer, T.M. 2003. Influenza $A$ virus surveillance in wild birds in Northern Europe in 1999 and 2000. Avi Dis. 47: 857-860.

Fouchier, R.A., Munster, V. \& Wallensten, A. 2005. Characterization of a novel influenza $A$ virus hemagglutinin subtype (H16) obtained from blackheaded gulls. J. Virology 79: 2814-2822.
Halvorson, D.A., Karunakaran, D., Senne, D., Zelleher, C., Bailey, C., Abraham, A., Hinshaw, V. \& Newman, G. 1983. Epizootiology of avian influenza simultaneous monitoring of sentinel ducks and turkeys in Minnesota. Avi Dis. 27: 77-85.

Nooruddin, G.M., Hossain, M.T., Mohammad, M. \& Rahman, M.M. 2006. Sero-Epidemiology of Avian Influenza Virus in Native Chicken in Bangladesh. Int. J. Poult Sci. 5 (11): 1029-1033.

Office International des Epizooties (OIE). 2003. Highly Pathogenic Avian Influenza. In terrestrial animal Health code. The Office International des Epizooties. www.oie.int.

Senne, D.A., Suarez, D.L., Pedersen, J.C. \& Panigrahy, B. 2003. Molecular and biological characteristics of $\mathrm{H} 5$ and $\mathrm{H} 7$ avian influenza Viruses in Live-Bird Markets of the Northeastern United States, 19942001. Avi Dis. 47: 898-904.

Sidorenko, Y. \& Reichl, U. 2004. Structured model of influenza virus replication in MDCK cells. Biotechnology and Bioengenearing 88: 1-14.

Songserm, T., Jam-on, R. \& Sae-Heng, N. 2006. Domestic ducks and H5N1 influenza epidemic, Thailand. Emer Inf Dis. 12 :575-581.

Tiensin, T., Chaitaweesub, P. \& Songserm, T. 2005. Highly pathogenic avian influenza H5N1, Thailand, 2004. Emer Inf Dis. 11: 1664-1672.

Vander, G.V.A., Kach, G., Gong, M.C.M. \& Boven, M.V. 2003. Transmission dynamics of low and high pathogenicity A/chicken/Pennsylvania/83 avian influenza viruses. Avi Dis. 47: 939-941.

Webster, R.G., Peiris, M., Chen, H. \& Guan, Y. 2006. H5N1 outbreaks and enzootic influenza. Emer Inf Dis. 12: 3-8. 